DR. INGRID ROWLANDS (Orcid ID : 0000-0002-7889-891X) Article type : Main research article

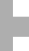

\title{
Prevalence and incidence of endometriosis in Australian women: a data linkage cohort study
}

Running title: Prevalence of endometriosis in Australia

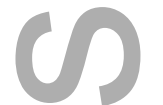

IJ Rowlands, *, JA Abbott ${ }^{\mathrm{b}}$, GW Montgomery ${ }^{\mathrm{c}}$, R Hockey ${ }^{\mathrm{a}}$, P Rogers ${ }^{\mathrm{d}}$, and GD Mishra ${ }^{\mathrm{a}}$ aSchool of Public Health, The University of Queensland, Herston, QLD 4006, Australia

bSchool of Women's and Children's Health, University of New South Wales, Randwick, NSW 2052, Australia

'Institute for Molecular Bioscience, The University of Queensland, St Lucia, QLD 4072, Australia

dDepartment of Obstetrics and Gynaecology and Gynaecology Research Centre, Royal Women's Hospital, University of Melbourne, Parkville, Victoria 3010, Australia.

*Corresponding Author: Email: i.rowlands@uq.edu.au. Phone: +617 3365 5598. Postal Address: The Uniyersity of Queensland, School of Public Health, Herston QLD 4006, Australia

\section{Abstract}

Objective: To estimate the prevalence and incidence of endometriosis among Australian women.

Design: Population-based cohort study linked to administrative health records.

Setting: Secondary analysis of seven surveys collected between 2000 and 2018 from a population-based cohort study.

This is the author manuscript accepted for publication and has undergone full peer review but has not been through the copyediting, typesetting, pagination and proofreading process, which may lead to differences between this version and the Version of Record. Please cite this article as doi: 10.1111/1471-0528.16447

This article is protected by copyright. All rights reserved 
Population: 13,508 Australian women, born 1973-1978, from a prospective cohort study of 14,247 women conducted between 1996 and 2018.

Methods: During 2000 and 2018, self-reported longitudinal survey data were linked to three administrative health databases to separately identify women with clinically confirmed or suspected endometriosis across the multiple data sources.

Main Outcome Measures: Prevalence and incidence of clinically confirmed endometriosis in the cohort was first estimated using national hospital data. Data were then combined with other administrative health databases and the survey data to capture all clinically confirmed and suspected diagnoses of endometriosis.

Results: The cumulative prevalence of clinically confirmed endometriosis was $6.0 \%(95 \% \mathrm{CI}$ $5.8 \%-6.2 \%)$ by age $40-44$ years. The cumulative prevalence increased to $11.4 \%(95 \% \mathrm{CI}$ $11.1 \%-11.7 \%$ ) when adding diagnoses of clinically suspected endometriosis. Age-specific incidence estimates peaked to 6 per 1000 person-years at age 30-34 years.

Conclusions: Among 13,508 Australian women followed for 20 years, one in nine women had clinically confirmed or suspected endometriosis by the age of 44, with most diagnosed during their early thirties. Endometriosis is significant public health issue requiring increased surveillance, clinical awareness and management. Efforts to expand knowledge on the aetiology of the disease and optimal methods for disease management are crucial to women's health.

Funding: IJR was supported by a Commonwealth of Australia Medical Research Future Fund Grant (MRFF-END) administered by Jean Hailes for Women's Health. GDM and GWM are funded by an Australian National Health and Medical Research Council Principal Research Fellowships (GNT1121844 and GNT1078399). The ALSWH is funded by the Australian Government Department of Health.

Keywords: endometriosis, prevalence, incidence, epidemiology, cohort study

Tweetable abstract: In a national study of 13,508 Australian women one in nine women were diagnosed with endometriosis by age 44 .

\section{Introduction}

The aetiology of endometriosis is poorly understood and consistent risk factors for the onset and progression of endometriosis have not been established. Because the gold standard for the diagnosis of endometriosis involves surgery and histological confirmation, it is often 
difficult to identify women in the population who may be living with the disease ${ }^{1}$. The prevalence of endometriosis is estimated to be $10 \%{ }^{1,2}$. This estimate is based on a US study from the 1980s that evaluated the hospital records of 858 women undergoing vaginal hysterectomy for reasons other than endometriosis ${ }^{3}$. A separate US cohort study reported a prevalence of $11.5 \%$ using national hospitalisation records during 1987 to $1999^{4}$. Although more recent prevalence estimates are considerably lower at around 1-2\%, differences across studies, including the ascertainment of cases, source of data and study design make it difficult to compare prevalence rates over time ${ }^{7}$. Studies using short observation periods to identify cases of endometriosis may be particularly susceptible to low prevalence estimates because long diagnostic delays are common.

Annual incidence rates for endometriosis across studies are also inconsistent - from 0.7 to 4 cases per 1000 person-years ${ }^{4-6,8-11}$ - with differences due to varying study designs, including the timing and length of study observation periods. Changes to the clinical diagnosis and classification of endometriosis, and increased public awareness of the disease both within and across countries over time may have also influenced incidence rates.

Population-based estimates of the prevalence and incidence of endometriosis are scarce and currently unavailable in Australia. Recently, there has been a 'philosophical shift' in the diagnostic paradigm ${ }^{12}$ where the clinical diagnosis of endometriosis is increasingly accurate and may offer a sound alternative to the traditional, but invasive surgical diagnostic approach $^{13}$. This is an important shift for understanding the epidemiology of the disease. In response to the broadening diagnostic paradigm for endometriosis, and the need for highquality prevalence data, the present study combines 20 years of national survey data from 13,508 Australian women with their administrative health records to identify women with clinically confirmed or suspected endometriosis. We estimate the national prevalence and incidence of clinically confirmed endometriosis alone, and with the addition of women with clinically suspected endometriosis

\section{Methods}

Data are from the Australian Longitudinal Study on Women's Health (ALSWH). ALSWH is a national study focusing on the biological, psychological, social and economic factors relevant to women's health. The entire study involves three age cohorts of women who were randomly selected from the database of Medicare (Australia's universal health insurance system), with oversampling from rural and remote areas of Australia. Medicare includes all Australian citizens and permanent residents, and is believed to be the most 
complete and up-to-date population list in Australia. This study focuses on the young cohort of women, born between 1973-78, and aged 18-23 years when first surveyed in 1996. Approximately every three years since 1996, participants have completed postal or online surveys about their health and wellbeing. In 2012, approval was obtained to link survey data to women's administrative health records. Detailed information on the study methods have been published elsewhere ${ }^{14}$. Participants were not involved in the study design or the recruitment process. However, ALSWH findings are disseminated to participants via newsletters, the ALSWH website and social media.

ALSWH study participants have been followed for more than 20 years. Participants were assigned with a unique study identification number to enable longitudinal analysis of individual survey data. Data are continuously monitored and maintained by the study team. Surveys, data dictionaries, and study publications are publicly available via the study website http://www.alswh.org.au. While new questions have been added to surveys over the years, a set of core questions and validated measures for each cohort were retained to facilitate longitudinal analysis and establish cause-and-effect associations. A question about endometriosis remained essentially the same across the surveys, offering a unique opportunity to examine the prevalence and incidence of the disease.

\section{Ethical approval}

ALSWH was originally approved by the Human and Research Ethics Committees (HREC) of the University of the Newcastle (UoN) in 1995 (Clearance number: H 076 0795) and The University of Queensland (UQ) in 2004 (reference number: 2004000 224). The most recent amendment for ALSWH Survey 8 of the 1973-78 cohort was approved by UoN HREC on 8 November 2017 and ratified by UQ HREC on 9 November 2017. Ethical approval for data linkage was obtained from the UoN HREC on 31 January 2012 (Clearance Number: H-20110371) and from the UQ HREC on 9 February 2012 (Number: 2012000132).

\section{Funding}

The research was supported a Commonwealth of Australia Medical Research Future Fund Grant (MRFF-END). The funder had no role in conducting the research or writing the paper.

\section{Participants}

There were 14,247 women born in 1973-78 who responded to a baseline survey in 1996 (aged 18-23 years), with an estimated response of approximately 41-42\% (see Figure S1). Since then, response rates to specific surveys have ranged from $69 \%$ to $57 \%$ (see Figure 
S1). Because women who miss surveys are invited to participate in subsequent surveys, the overall cohort survey response rate has remained relatively stable at around $80 \%{ }^{14}$.

Of the 14,247 women who entered the cohort, 13,508 (95\%) women agreed to have their data linked to their administrative health records and were retained for analysis. Of these, $11,235(83 \%)$ responded to at least one survey question about endometriosis (with the remaining $17 \%$ of women still available for data linkage). Of the 11,235 women who responded an endometriosis survey question, 93\% responded to at least two questions and $54 \%$ responded to all seven questions.

\section{Data sources used to identify endometriosis}

Women participating in the ALSWH survey were first asked about endometriosis in 2000 (Survey 2): "Have you ever been told by a doctor that you have: Endometriosis?" At the subsequent six surveys (completed every three years from 2003 to 2018) women were asked, "In the last 3 years, have you ever been diagnosed or treated for: endometriosis?" Women's responses to the survey data in conjunction with three administrative health databases were used to identify women with clinically confirmed or suspected endometriosis (see Table S1). Databases included the Medical Benefits Scheme (MBS), which includes healthcare services subsidised under Medicare (Australia's universal health insurance system); Pharmaceutical Benefits Scheme (PBS), including medications subsidised under Medicare that are dispensed to the population and the Admitted Patient Data Collection (Hospital data), which contains records for all hospital separations from public and private hospitals and day procedure centres. Details of these data sources and the codes used to identify endometriosis in each source are presented in Table S1. Because we used four data sources (all linked to individual women), women could be identified as having endometriosis from one or multiple sources.

Clinically confirmed endometriosis included women who had a hospital discharge diagnosis of endometriosis, coded using the International Classification of Diseases, $9^{\text {th }}$ Revision, Clinical Modification (ICD-9-CM) or $10^{\text {th }}$ revision, Australian modification (ICD10-AM), as recorded in the hospital data. Clinically suspected endometriosis included women who only had a record of endometriosis in the ALSWH survey data (i.e. they responded "yes" to ever being treated or diagnosed by a doctor for endometriosis), or who only had a record of endometriosis in the MBS or PBS data. Across the data sources, the date of hospital admission (hospital data), health service use date (MBS data), medication dispense date (PBS data), or the date of survey completion (ALSWH data) was used to identify women's earliest date of diagnosis.

\section{Assessment of women's baseline characteristics.}


At the baseline ALSWH survey when women were aged 18-23 years, sociodemographic information was collected including area of residence based on an index of distance to the nearest urban centre (urban vs. rural/remote) ${ }^{15}$; highest level of education (year 12 or less, trade/certificate/diploma, university degree) and current relationship status (single, married/defacto partnership). Information was collected on reproductive health including age at menarche $(\leq 11,12-14, \geq 15$ years), parity (yes/no), and contraceptive use. Women were also asked to report their weight in childhood when they were aged 10 years (underweight, average, overweight) and current weight and height, which was used to calculate body mass index $\left[\left(\mathrm{BMI} ; \mathrm{kg} / \mathrm{m}^{2}\right)\right.$, categorised as underweight $\left(<18.5 \mathrm{~kg} / \mathrm{m}^{2}\right)$, normal weight $\left(18.5-24.9 \mathrm{~kg} / \mathrm{m}^{2}\right)$, overweight or obese $\left(\geq 25 \mathrm{~kg} / \mathrm{m}^{2}\right)$. They were asked about smoking (classified as never, ex-smoker, current smoker) and their physical health using the General Health Subscale of the SF- $36^{16}$.

\section{Statistical analysis}

We first calculated the cumulative prevalence of clinically confirmed endometriosis using linked hospital data. A cumulative prevalence was calculated by retaining a woman following her first hospital admission that identified endometriosis. The first date of hospital admission was used to calculate the woman's age at diagnosis. Prevalence was first calculated by single year of age and then collapsed into five-year age groups. We first calculated prevalence by state of admission as the availability of hospital data varied across states. Because prevalence rates were not appreciably different by state (data not shown), we combined all hospital data.

The cumulative prevalence of clinically confirmed endometriosis and clinically suspected endometriosis was then calculated by including additional cases from the ALSWH Survey data or MBS or PBS databases. A cumulative prevalence was calculated by retaining a woman following her first record of endometriosis, which was either from the survey or one of the administrative databases (whichever came first). Because recruitment of the 1973-78 cohort over-sampled women from rural and remote areas, all estimates were weighted by area of residence based on 1996 Australian Census data for women of the same age. Prevalence was calculated by single year of age (data not shown) and then collapsed into five-year age groups. Sensitivity analyses excluding hospital records of endometriosis of the uterus to remove women with adenomyosis (codes: N80.0, 617.0) were also completed.

Similarly, the incidence of clinically confirmed endometriosis was first calculated using the hospital data. Following this, the incidence of clinically confirmed endometriosis 
and clinically suspected endometriosis was then calculated by including additional cases from the ALSWH Survey data or MBS or PBS databases. Incidence was calculated by identifying the number of new cases and dividing that by the estimated total number of years accrued by the contributing cases across the 20-year period, expressed as per 1,000 person-years. Incidence was first calculated by single year of age (data not shown) and then collapsed into five-year age groups and data were weighted by area of residence. Due to the low incidence rates, confidence intervals were calculated using a logit transformation to remove negative numbers ${ }^{17}$.

Bivariate logistic regression was used to compare the baseline characteristics of women included in this study with, and without, a record of clinically confirmed or suspected endometriosis. We also compared the baseline characteristics of women with clinically suspected endometriosis only to women with clinically confirmed endometriosis. All statistical analyses were performed using SAS software version $9.4\left(\right.$ TS1M5) ${ }^{18}$.

\section{Results}

A total of 1,602 women with a record of clinically confirmed or suspected endometriosis were identified across the four data sources. Of these, $40 \%$ were identified from the ALSWH Survey data alone, 20\% from hospital data alone, and 24\% were present in both data sources (see Figure 1). The remaining 16\% of cases were identified through PBS data alone and various combinations of the four data sources (see Figure 1).

Table 1 compares women with, and without, clinically confirmed or suspected endometriosis at baseline (aged 18-23 years). Women with clinically confirmed or suspected endometriosis were more likely to be married, report earlier menarche ( $\leq 11$ years old) and have ever used the oral contraceptive pill than women without a diagnosis of endometriosis. They were less likely to be overweight in childhood (aged 10 years) and obese in adulthood, and less likely to report good levels of general health than women without endometriosis (see Table 1). Compared to women with clinically confirmed endometriosis, women with clinically suspected endometriosis were more likely to be overweight or obese and classified as a risky or high-risky drinker at age 18-23 years than women who had a diagnosis $(p<0.01)$.

A total of 842 women with clinically confirmed endometriosis were identified from the hospital data. The incidence of clinically confirmed endometriosis was 0.2 cases per 1000 person-years at age 20-24 years, peaking to 4 per 1000 person-years at 30-34 years (see Figure 2; blue bars). The cumulative prevalence of clinically confirmed endometriosis was 
$2.9 \%(95 \%$ CI 2.7\%-3.0\%) at 30-34 years and reached 6.0\% (95\% CI 5.8\%-6.2\%) by age $40-$ 44 years (see Figure 2; orange line).

Among all 1,602 cases, the incidence of clinically confirmed or suspected endometriosis was 0.2 per 1000 person-years at 20-24 years but increased to 6 per 1000 person-years at age 30-34 years (see Figure 3; blue bars). The cumulative prevalence of clinically confirmed or suspected endometriosis in the population was $11.4 \%$ (95\% CI 11.1\%-11.7\%) (see Figure 3; orange line). Sensitivity analyses excluding clinically confirmed endometriosis of the uterus to exclude possible diagnoses of adenomyosis without endometriosis did not significantly change the cumulative prevalence $(11.0 \%, 95 \% \mathrm{CI}$ 10.7\%-11.3\%). Exact numbers for incidence and prevalence among women with clinically confirmed or suspected endometriosis are presented in supplementary Tables S2 and S3.

\section{Discussion}

\section{Main Findings}

In this longitudinal cohort study spanning nearly 20 years, $11 \%$ of women received a diagnosis of clinically confirmed or suspected endometriosis by age $44{ }^{19}$. Of those diagnosed, $6 \%$ had clinically confirmed endometriosis and the remaining $5 \%$ had clinically suspected endometriosis. The age that women were first diagnosed with clinically confirmed or suspected endometriosis peaked at 30-34 years.

\section{Strengths and Limitations}

In this national, longitudinal Australian cohort, we had the advantage of repeat data from women with clinically confirmed and suspected endometriosis available over 20 years. The use of multiple sources of data meant we could distinguish clinically confirmed endometriosis from clinically suspected endometriosis in the population, which would not have been possible if we had relied on one data source alone. In our study, $40 \%$ of women only received a suspected diagnosis of endometriosis. The inclusion of these women may over-estimate disease prevalence, although their exclusion may under-estimate prevalence since historically, the limited social and clinical awareness of the disease has contributed to long diagnostic delays ${ }^{12,20}$. Additionally, surgical confirmation of endometriosis is not always undertaken due to socioeconomic and healthcare disparities ${ }^{7}$. For example, in this study women with clinically suspected endometriosis were more likely to be overweight or obese at baseline than women with clinically confirmed endometriosis. Obesity may be a barrier to clinical confirmation of endometriosis because clinicians may not recognise the signs and symptoms among women who are obese, or may be hesitant to operate given the 
additional risks during surgery. The inclusion of women with clinically suspected endometriosis can therefore minimise any diagnostic bias that may arise in studies based solely on surgical samples.

Retention in the ALSWH cohort remains high at around $80 \%{ }^{14}$. Women who responded to the baseline survey and one other survey were included in our prevalence estimates since re-engaging women who miss surveys has been found to reduce bias, particularly in prevalence estimate ${ }^{21}$. This is because women who miss ALSWH surveys are similar on a range of characteristics to women who withdraw from the study ${ }^{21}$. Women who miss ALSWH surveys are more likely to report difficulty managing on their income, less likely to have a university education and more likely to be smokers than women who consistently respond ${ }^{22}$.

Comparisons with 5-yearly Australian Census data suggest this cohort of women broadly represent the same demographic in the broader Australian population, however there is an over-representation of women with a university education ${ }^{14}$. The role of education in the diagnosis of endometriosis is difficult to ascertain, with higher education associated with better general health ${ }^{22}$ that may result in the overall prevalence and incidence of endometriosis being underestimated. The corollary is that education is associated with better access to health services - potentially increasing women's chances of receiving a diagnosis of endometriosis - and overestimating prevalence.

Hospital data were not available for all states across the entire study period. Some women were also missed if they were treated in some private hospitals. Hospital data from the three largest Australian states showed that around half of the endometriosis cases were from private hospitals. While the larger states account for $92 \%$ of the Australian population ${ }^{23}$, the hospital estimates may slightly underestimate the prevalence of endometriosis.

Clinically, it is important to note that our estimates do not distinguish endometriosis and adenomyosis as the ICD coding for "endometriosis of the uterus" does not separate serosal endometriosis lesions to deep muscular glandular invasion (adenomyosis). We could not definitively separate these conditions in our estimates, which is consistent with previous studies also using hospital databases to estimate endometriosis prevalence and incidence ${ }^{4,5}$. We retained the ICD code for "endometriosis of the uterus" in our estimate as our sensitivity analyses excluding this ICD code did not change the overall prevalence. Removing it would risk losing women who in fact had endometriosis and not adenomyosis due to this classification anomaly. The definition of adenomyosis remains highly debated, even with histopathological examination 24,25 and the two conditions have similar symptom profiles and 
treatment strategies ${ }^{24-26}$. Endometriosis and adenomyosis co-exist in up to $80 \%$ of women, further blurring the boundaries of these two conditions ${ }^{24,26}$. Given these challenges in definitions and diagnosis, this singe code is included to provide the full spectrum of endometriosis prevalence.

\section{Interpretation}

Epidemiologic studies of endometriosis have faced substantial methodological challenges due to the variability of symptoms, symptom overlap with other conditions, long lag times from symptoms to diagnosis (7-12 years) and the need for surgery with histology to establish a definitive diagnosis ${ }^{7}$. These issues create considerable bias in prevalence estimates ${ }^{7}$. Until non-invasive methods of diagnosis are available, understanding the epidemiology of endometriosis will be challenging. Although surgery remains important in endometriosis diagnosis and lesion removal, the inflammatory nature of endometriosis means women's symptoms are increasingly prioritised and inform alternative treatment pathways ${ }^{12}$. Therefore, taking a broader diagnostic approach to estimating the epidemiology of endometriosis is critical. In this study, we used of multiple sources of information based on women's self-report data over 20 years, combined with their health records, to estimate the epidemiology of the endometriosis.

In this longitudinal cohort study, $6 \%$ of women were identified as having clinically confirmed endometriosis. Our estimate is consistent with another longitudinal cohort study, the US Nurses' Health Study II ${ }^{27}$, and similar to an earlier Australian study reporting a 7\% prevalence among 3,003 twins ${ }^{28}$. Our prevalence estimate is, however, considerably higher than other recent studies $5,6,8$. Differences in study designs, in combination with variations across countries regarding the diagnosis and treatment of endometriosis, make it difficult to compare across the research. In Australia, endometriosis hospitalisations have increased between 2007 and $2017^{19}$. Increasing health professional knowledge and training in endometriosis, which in turn can influence the classification and coding of endometriosis, may explain the high hospitalisations in this cohort of young Australian women.

Using all available data, $11 \%$ of women had a record of clinically confirmed or suspected endometriosis during the 20 -year period. This estimate is consistent with US prevalence estimates from more than a decade $\mathrm{ago}^{3,4,29}$. The methodological similarities including the linkage of administrative health records and a long follow-up period - may explain the similar prevalence estimates. Other recent studies, however, have estimated prevalence at one time point or observed women over a short period, producing low prevalence estimates $^{5,6}$. Because lengthy delays in diagnosis are common for women with 
endometriosis ${ }^{30}$, population-based studies with longer follow-up periods increase the potential to detect diagnoses of endometriosis in the population.

Consistent with patterns during the 1990s from the US ${ }^{4}$ and UK ${ }^{31}$, the incidence of clinically confirmed endometriosis in this study peaked at 30-34 years. Endometriosis diagnosed at this time may coincide with the average maternal age of a first birth being around 29 years in Australia ${ }^{32}$. Women experiencing difficulties becoming pregnant will most likely undergo fertility investigations at this time, increasing their chances of receiving a diagnosis of endometriosis.

\section{Conclusion}

In a national cohort of Australian women, around one in nine women were diagnosed with clinically confirmed or suspected endometriosis by age 44 . Of these, $6 \%$ of women had clinical confirmed endometriosis and an additional $5 \%$ of women had clinically suspected endometriosis. Endometriosis is a significant public health issue. Clinicians should be aware that they are highly likely to care for women with endometriosis. The physical and psychosocial burden of undiagnosed endometriosis has prompted professional societies to recommend clinical diagnosis and treatment of endometriosis without surgical intervention ${ }^{12}$. There is, however, limited information about how to tailor treatment to offer optimal prognostic outcomes based on women's symptoms and associated risk factors. Establishing prevalence is an important, initial step towards building a strong foundation of research that can expand knowledge on disease aetiology, progression and management. Evidence is key to informing clinical guidelines for earlier diagnosis and optimal treatment of endometriosis.

\section{Acknowledgements}

The research on which this paper is based was conducted as part of the Australian Longitudinal Study on Women's Health by the University of Queensland and the University of Newcastle. We are grateful to the Australian Government Department of Health for funding and to the women who provided the survey data.

The authors acknowledge the Department of Health and Medicare Australia for providing MBS and PBS data, and the Australian Institute of Health and Welfare (AIHW) as the integrating authority. The authors also acknowledge the following:

- Centre for Health Record Linkage (CHeReL), NSW Ministry of Health and ACT Health, for the NSW Admitted Patients Data Collection, and the ACT Admitted Patient Care Data Collections 
- Queensland Health, including the Statistical Services Branch, for the Qld Hospital Admitted Patient Data Collection

- Department of Health Western Australia, including the Data Linkage Branch, and the WA Hospital Morbidity Data Collection

- *SA NT Datalink, and SA Health and Northern Territory Department of Health, for the SA Public Hospital Separations and NT Public Hospital Inpatient Activity Data Collections

- *Tasmanian Data Linkage Unit, and the Department of Health and Human Services Tasmania, for the Public Hospital Admitted Patient Episodes Data Collection

- *Centre for Victorian Data Linkage, Department of Health and Human Services Victoria, for the Victorian Admitted Episodes Data Collection

*This project is supported by the Population Health Research Network which is a capability of the Australian Government National Collaborative Research Infrastructure Strategy and Education Investment Fund Super Science Initiative.

\section{Disclosure of Interests}

Dr Rowlands was supported by a fellowship from Commonwealth of Australia Medical Research Future Fund Grant (MRFF-END) during the conduct of the study.

All other authors have no conflicts to disclose. Completed disclosure of interest forms are available to view online as supporting information.

\section{Contribution to Authorship}

IJR made substantial contributions to the design of the study, conducted the statistical analyses and drafted the manuscript. RH made substantial contributions to the design of the study, conducted the statistical analyses and critically reviewed the manuscript for intellectual content. JA, GM, and PR contributed to the interpretation of the results and critically reviewed the manuscript for intellectual content. GDM made substantial contributions to the conception and design of the study and statistical analyses, contributed to the interpretation of the results, and critically reviewed the manuscript for intellectual content. All authors read and approved the final manuscript.

\section{Details of ethics approval}

ALSWH was originally approved by the Human and Research Ethics Committees (HREC) of the University of the Newcastle (UoN) in 1995 (Clearance number: H 076 0795) and The University of Queensland (UQ) in 2004 (reference number: 2004000 224). The most recent 
amendment for ALSWH Survey 8 of the 1973-78 cohort was approved by UoN HREC on 8 November 2017 and ratified by UQ HREC on 9 November 2017. Ethical approval for data linkage was obtained from the UoN HREC on 31 January 2012 (Clearance Number: H-20110371) and from the UQ HREC on 9 February 2012 (Number: 2012000132).

\section{Funding}

IJR was supported by a Commonwealth of Australia Medical Research Future Fund Grant (MRFF-END) administered by Jean Hailes for Women's Health. GDM and GWM are funded by an Australian National Health and Medical Research Council Principal Research Fellowships (GNT1121844 and GNT1078399). The ALSWH is funded by the Australian Government Department of Health.

\section{References}

1. Zondervan KT, Becker CM, Missmer SA. Endometriosis. N Engl J Med. 2020;382(13):1244-56.

2. Giudice LC. Clinical practice. Endometriosis. N Engl J Med. 2010;362(25):2389-98.

3. Wheeler JM. Epidemiology of endometriosis-associated infertility. J Reprod Med. $1989 ; 34(1): 41-6$.

4. Leibson CL, Good AE, Hass SL, Ransom J, Yawn BP, O'Fallon WM, et al. Incidence and characterization of diagnosed endometriosis in a geographically defined population. Fertil Steril. 2004;82(2):314-21.

5. Eisenberg VH, Weil C, Chodick G, Shalev V. Epidemiology of endometriosis: a large population-based database study from a healthcare provider with 2 million members. BJOG. 2018;125(1):55-62.

6. Abbas S, Ihle P, Koster I, Schubert I. Prevalence and incidence of diagnosed endometriosis and risk of endometriosis in patients with endometriosis-related symptoms: findings from a statutory health insurance-based cohort in Germany. Eur J Obstet Gynecol Reprod Biol. 2012;160(1):79-83.

7. Shafrir AL, Farland LV, Shah DK, Harris HR, Kvaskoff M, Zondervan K, et al. Risk for and consequences of endometriosis: A critical epidemiologic review. Best Pract Res Clin Obstet Gynaecol. 2018;51:1-15.

8. Morassutto C, Monasta L, Ricci G, Barbone F, Ronfani L. Incidence and Estimated Prevalence of Endometriosis and Adenomyosis in Northeast Italy: A Data Linkage Study. PLoS One. 2016;11(4):e0154227. 
9. Gylfason JT, Kristjansson KA, Sverrisdottir G, Jonsdottir K, Rafnsson V, Geirsson RT. Pelvic endometriosis diagnosed in an entire nation over 20 years. Am J Epidemiol. 2010;172(3):237-43.

10. Houston DE, Noller KL, Melton LJ, 3rd, Selwyn BJ, Hardy RJ. Incidence of pelvic endometriosis in Rochester, Minnesota, 1970-1979. Am J Epidemiol. 1987;125(6):959-69. 11. Shah DK, Correia KF, Vitonis AF, Missmer SA. Body size and endometriosis: results from 20 years of follow-up within the Nurses' Health Study II prospective cohort. Hum Reprod. 2013;28(7):1783-92.

12. Agarwal SK, Chapron C, Giudice LC, Laufer MR, Leyland N, Missmer SA, et al. Clinical diagnosis of endometriosis: a call to action. Am J Obstet Gynecol. 2019;220(4):354 e1- e12.

13. Taylor HS, Adamson GD, Diamond MP, Goldstein SR, Horne AW, Missmer SA, et al. An evidence-based approach to assessing surgical versus clinical diagnosis of symptomatic endometriosis. Int J Gynaecol Obstet. 2018;142(2):131-42.

14. Dobson AJ, Hockey R, Brown WJ, Byles JE, Loxton DJ, McLaughlin D, et al. Cohort Profile Update: Australian Longitudinal Study on Women's Health. Int J Epidemiol. 2015. 15. Australian Institute of Health and Welfare (AIHW). Rural, regional and remote health: a guide to remoteness classifications. Canberra: AIHW; 2004.

16. McCallum J. The SF-36 in an Australian sample: validating a new, generic health status measure. Australian Journal of Public Health. 1995;19(2):160-6.

17. Curtin LR, D. Kruszon-Moran, M. Carroll, X. Li. Estimation and Analytic Issues for Rare Events in NHANES. Proceedings of the Survey Research Methods Section, American Statistical Association,; 2006.

18. SAS Institute Inc. Cary, NC, USA; 2016.

19. Australian Institute of Health and Welfare. Endometriosis in Australia: prevalence and hospitalisations. Cat. no. PHE 247. Canberra: AIHW; 2019.

20. Young K, Fisher J, Kirkman M. Women's experiences of endometriosis: a systematic review and synthesis of qualitative research. The journal of family planning and reproductive health care. 2015;41(3):225-34.

21. Powers J, Tavener M, Graves A, Loxton D. Loss to follow-up was used to estimate bias in a longitudinal study: a new approach. J Clin Epidemiol. 2015;68(8):870-6.

22. Powers J, Loxton D. The impact of attrition in an 11-year prospective longitudinal study of younger women. Ann Epidemiol. 2010;20(4):318-21. 
23. Australian Bureau of Statistics. Australian Demographic Statistics, Sep 2019: 3101.0. Canberra, Australia: ABS; 2019.

24. Chapron C, Vannuccini S, Santulli P, Abrao MS, Carmona F, Fraser IS, et al.

Diagnosing adenomyosis: an integrated clinical and imaging approach. Human reproduction update. 2020;26(3):392-411.

25. Gordts S, Grimbizis G, Campo R. Symptoms and classification of uterine adenomyosis, including the place of hysteroscopy in diagnosis. Fertil Steril. 2018;109(3):380-8 e1.

26. Abbott JA. Adenomyosis and Abnormal Uterine Bleeding (AUB-A)-Pathogenesis, diagnosis, and management. Best Pract Res Clin Obstet Gynaecol. 2017;40:68-81.

27. Prescott J, Farland LV, Tobias DK, Gaskins AJ, Spiegelman D, Chavarro JE, et al. A prospective cohort study of endometriosis and subsequent risk of infertility. Hum Reprod. 2016;31(7):1475-82.

28. Treloar SA, Do KA, O'Connor VM, O'Connor DT, Yeo MA, Martin NG. Predictors of hysterectomy: an Australian study. Am J Obstet Gynecol. 1999;180(4):945-54.

29. Velebil P, Wingo PA, Xia Z, Wilcox LS, Peterson HB. Rate of hospitalization for gynecologic disorders among reproductive-age women in the United States. Obstet Gynecol. 1995;86(5):764-9.

30. Ballard KD, Seaman HE, de Vries CS, Wright JT. Can symptomatology help in the diagnosis of endometriosis? Findings from a national case-control study--Part 1. BJOG. 2008;115(11):1382-91.

31. Missmer SA, Hankinson SE, Spiegelman D, Barbieri RL, Marshall LM, Hunter DJ. Incidence of laparoscopically confirmed endometriosis by demographic, anthropometric, and lifestyle factors. Am J Epidemiol. 2004;160(8):784-96.

32. Australian Institute of Health and Welfare. Australia's mothers and babies 2015 - in brief. Perinatal statistics series no. 33. Cat no. PER 91. Canberra; 2017.

\section{Table/Figure Caption List}

Table 1. Baseline characteristics of women (aged 18-23 years) with, and without, a record of endometriosis $(\mathrm{N}=13,508)$

Figure 1. Percentage of total endometriosis cases identified by different combinations of four data sources $(\mathrm{N}=1,602)$

Figure 2. Incidence and cumulative prevalence of clinically confirmed endometriosis, by age 
Figure 3. Incidence and cumulative prevalence of clinically confirmed and suspected endometriosis, by age

Table S1. Sources of data and codes used to identify cases of endometriosis

Table S2. Cumulative prevalence of clinically confirmed and suspected endometriosis, by age $(\mathrm{N}=13,508)$

Table S3. Age-specific incidence of clinically confirmed and suspected endometriosis

Figure S1. Participation, retention and attrition in the 1973-78 cohort

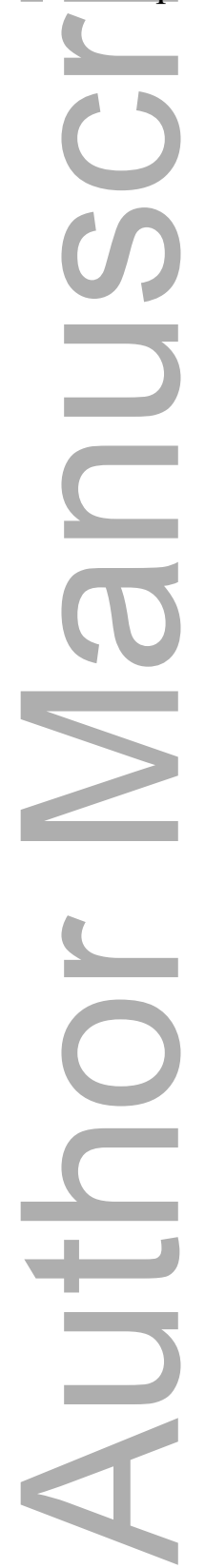


Table 1. Baseline characteristics of women (aged 18-23 years) with and without a record of endometriosis $(\mathrm{N}=13,508)$

\begin{tabular}{|c|c|c|c|c|c|}
\hline \multirow{2}{*}{ צי } & \multicolumn{2}{|c|}{$\begin{array}{l}\text { Endometriosis } \\
\qquad(\mathrm{n}=\mathbf{1 , 6 0 2})\end{array}$} & \multicolumn{2}{|c|}{$\begin{array}{l}\text { No endometriosis } \\
\qquad(\mathrm{n}=11,906)\end{array}$} & \multirow{2}{*}{$\begin{array}{c}\text { Endometriosis } \\
\text { Odds ratio }(95 \% \mathrm{CI})\end{array}$} \\
\hline & $\mathbf{n}$ & $\%$ & $\mathbf{n}$ & $\%$ & \\
\hline \multicolumn{6}{|l|}{ Sociodemographics } \\
\hline \multicolumn{6}{|l|}{ Age(years) } \\
\hline $18-19$ & 525 & 32.8 & 4,095 & 34.4 & 1 \\
\hline $20-21$ & 628 & 39.2 & 4,709 & 39.6 & $1.04(0.92-1.18)$ \\
\hline $22-23$ & 449 & 28.0 & 3,102 & 26.1 & $1.13(0.99-1.29)$ \\
\hline \multicolumn{6}{|l|}{ Marital Status } \\
\hline Single & 1,197 & 75.2 & 9,198 & 77.6 & 1 \\
\hline Defacto/Married & 395 & 24.8 & 2,653 & 22.4 & $1.14(1.01-1.29)$ \\
\hline \multicolumn{6}{|l|}{ Education } \\
\hline$<=$ Year 12 & 1129 & 70.8 & 8,406 & 71.0 & 1 \\
\hline Certificate/Diplc & 287 & 18.0 & 2,114 & 17.9 & $1.01(0.88-1.16)$ \\
\hline University & 178 & 11.2 & 1,317 & 11.1 & $1.01(0.85-1.19)$ \\
\hline \multicolumn{6}{|l|}{ Reproductive health } \\
\hline \multicolumn{6}{|l|}{ Age at menarche } \\
\hline$\leq 11$ & 210 & 16.8 & 1,001 & 12.9 & $1.36(1.15-1.60)$ \\
\hline $12-14$ & 903 & 72.3 & 5,831 & 74.9 & 1 \\
\hline$\geq 15$ & 136 & 10.9 & 956 & 12.3 & $0.92(0.76-1.11)$ \\
\hline \multicolumn{6}{|l|}{ Births } \\
\hline No & 1,443 & 90.7 & 10,645 & 90.1 & 1 \\
\hline Yes & 148 & 9.3 & 1,170 & 9.9 & $0.93(0.78-1.12)$ \\
\hline \multicolumn{6}{|l|}{ OC pill use } \\
\hline Never used & 316 & 19.9 & 3,443 & 29.1 & 1 \\
\hline Ever used & 1275 & 80.1 & 8,395 & 70.9 & $1.65(1.45-1.88)$ \\
\hline \multicolumn{6}{|c|}{ Childhood and adult weight } \\
\hline \multicolumn{6}{|l|}{ Weight at 10 years } \\
\hline Underweight & 432 & 27.4 & 2,883 & 24.5 & $1.11(0.98-1.26)$ \\
\hline Average & 848 & 53.8 & 6,278 & 53.4 & 1 \\
\hline
\end{tabular}




\begin{tabular}{|c|c|c|c|c|c|}
\hline & \multicolumn{2}{|c|}{$\begin{array}{l}\text { Endometriosis } \\
(\mathrm{n}=\mathbf{1 , 6 0 2})\end{array}$} & \multicolumn{2}{|c|}{$\begin{array}{l}\text { No endometriosis } \\
(\mathbf{n}=\mathbf{1 1 , 9 0 6 )}\end{array}$} & \multirow{2}{*}{$\begin{array}{c}\text { Endometriosis } \\
\text { Odds ratio }(95 \% \mathrm{CI})\end{array}$} \\
\hline & $\mathbf{n}$ & $\%$ & $\mathbf{n}$ & $\%$ & \\
\hline Overweight & 297 & 18.8 & 2,590 & 22.0 & $0.85(0.74-0.98)$ \\
\hline \multicolumn{6}{|c|}{ Current Body Mass Index $\left(\mathrm{kg} / \mathrm{m}^{2}\right)$} \\
\hline Underweight $(<18.5)$ & 158 & 9.9 & 989 & 8.3 & $1.21(0.94-1.34)$ \\
\hline Normal (18.5-24.9) & 1,003 & 62.6 & 7,039 & 59.1 & 1 \\
\hline Overweight (25-29.9) & 209 & 13.0 & 1,608 & 13.5 & $0.91(0.78-1.07)$ \\
\hline Obese $(\geq 30)$ & 62 & 3.9 & 699 & 5.9 & $0.62(0.48-0.81)$ \\
\hline \multicolumn{6}{|c|}{ Smoking and physical health } \\
\hline \multicolumn{6}{|l|}{ Smoking } \\
\hline Never & 814 & 52.8 & 5,916 & 52.0 & 1 \\
\hline Ex-smoker & 256 & 16.6 & 1,724 & 15.1 & $1.08(0.93-1.25)$ \\
\hline \multirow[t]{2}{*}{ Current } & 472 & 30.6 & 3,745 & 32.9 & $0.92(0.81-1.03)$ \\
\hline & Mean & $\mathrm{SD}$ & Mean & $\mathrm{SD}$ & \\
\hline SF-36 General Health & 64.5 & 21.8 & 68.9 & 20.4 & $0.91(0.88-0.93)$ \\
\hline
\end{tabular}

Note. Endometriosis includes women with clinically confirmed or suspected disease. Numbers may not sum to total because some data missing. OC pill = Oral contraceptive pill.

${ }^{a}$ Age at menarche was first asked at Survey 2 so the total number of women available for analysis was small

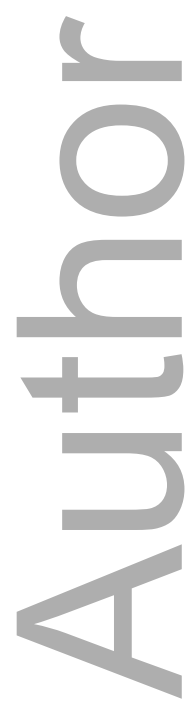

This article is protected by copyright. All rights reserved 

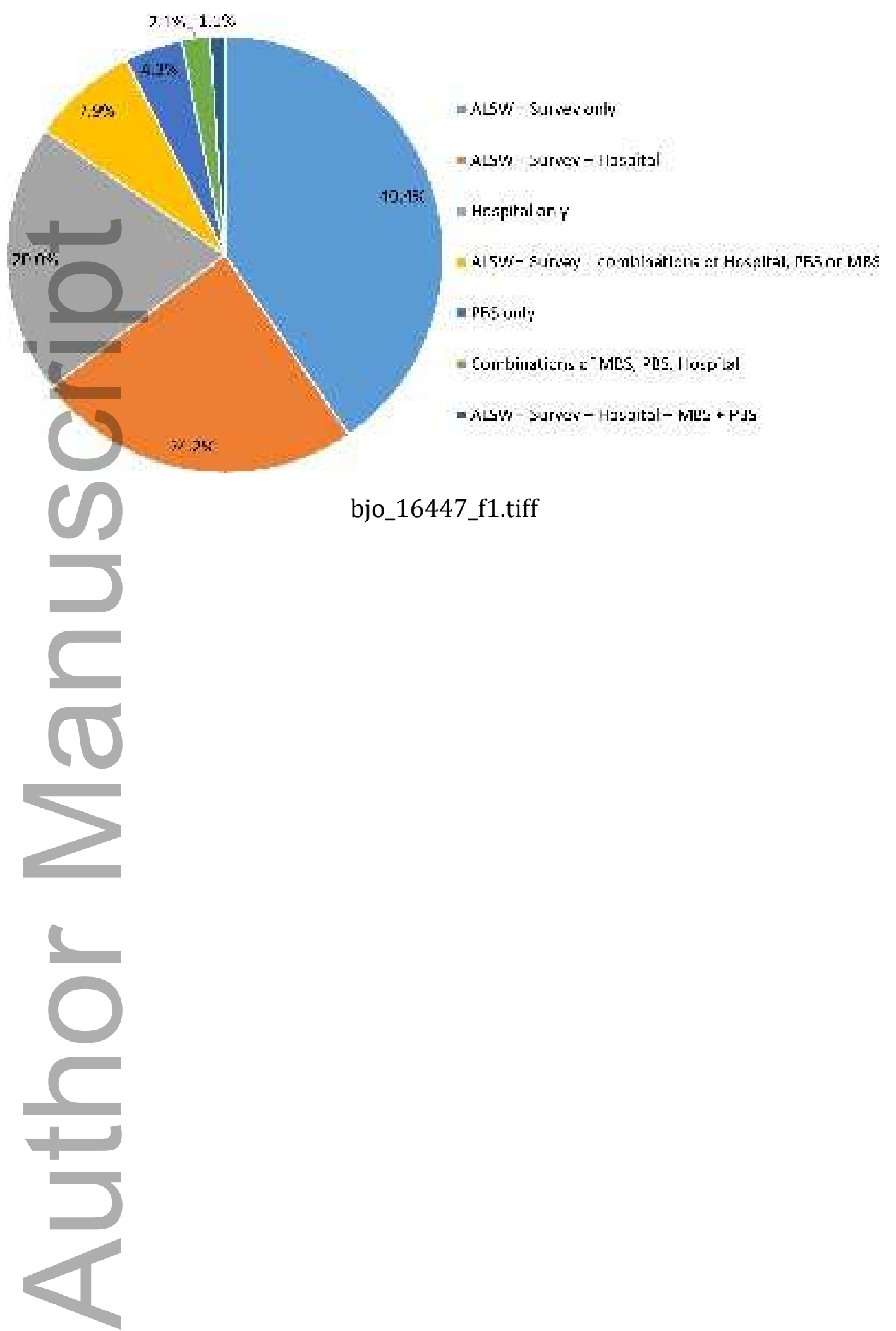

This article is protected by copyright. All rights reserved 

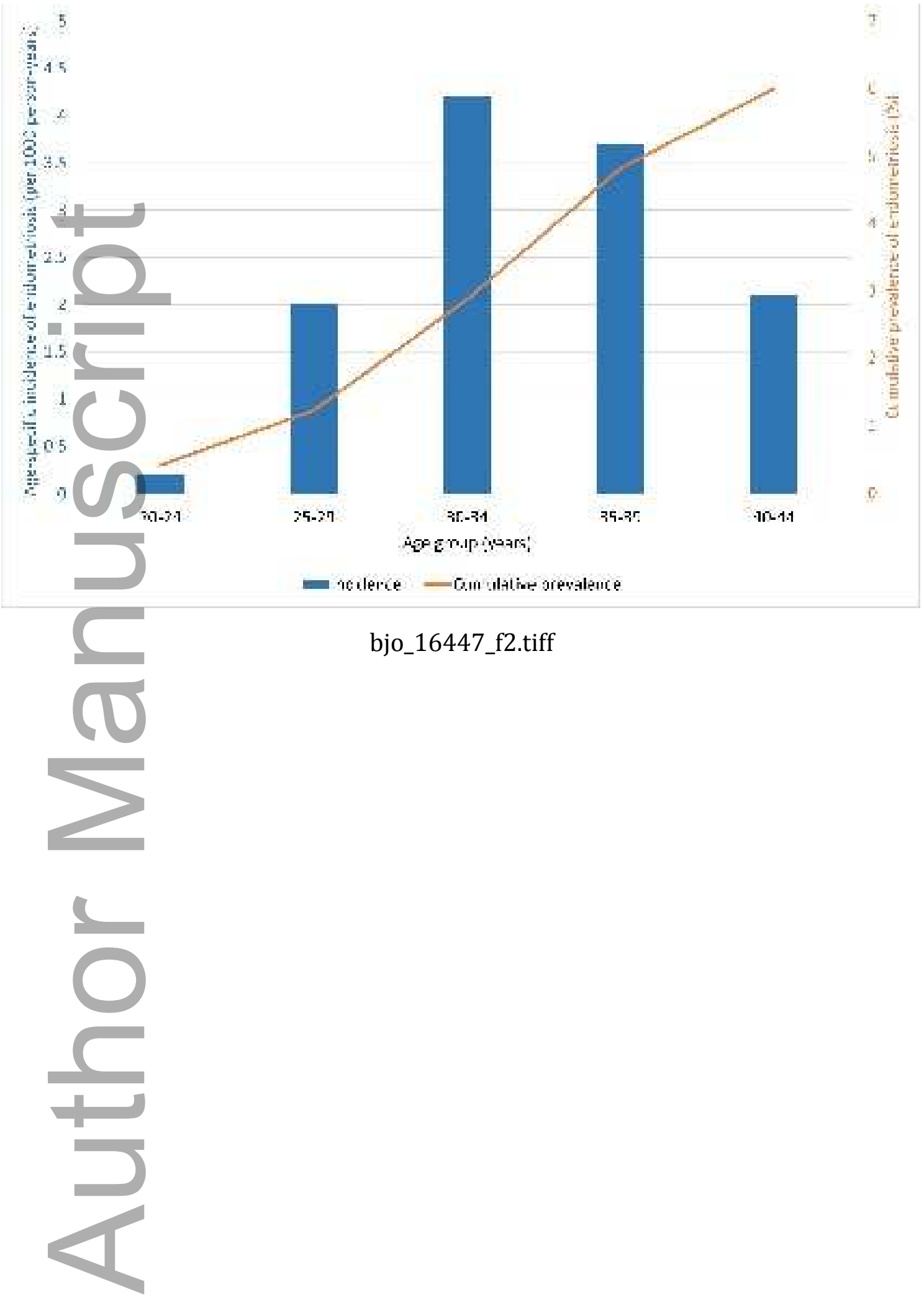


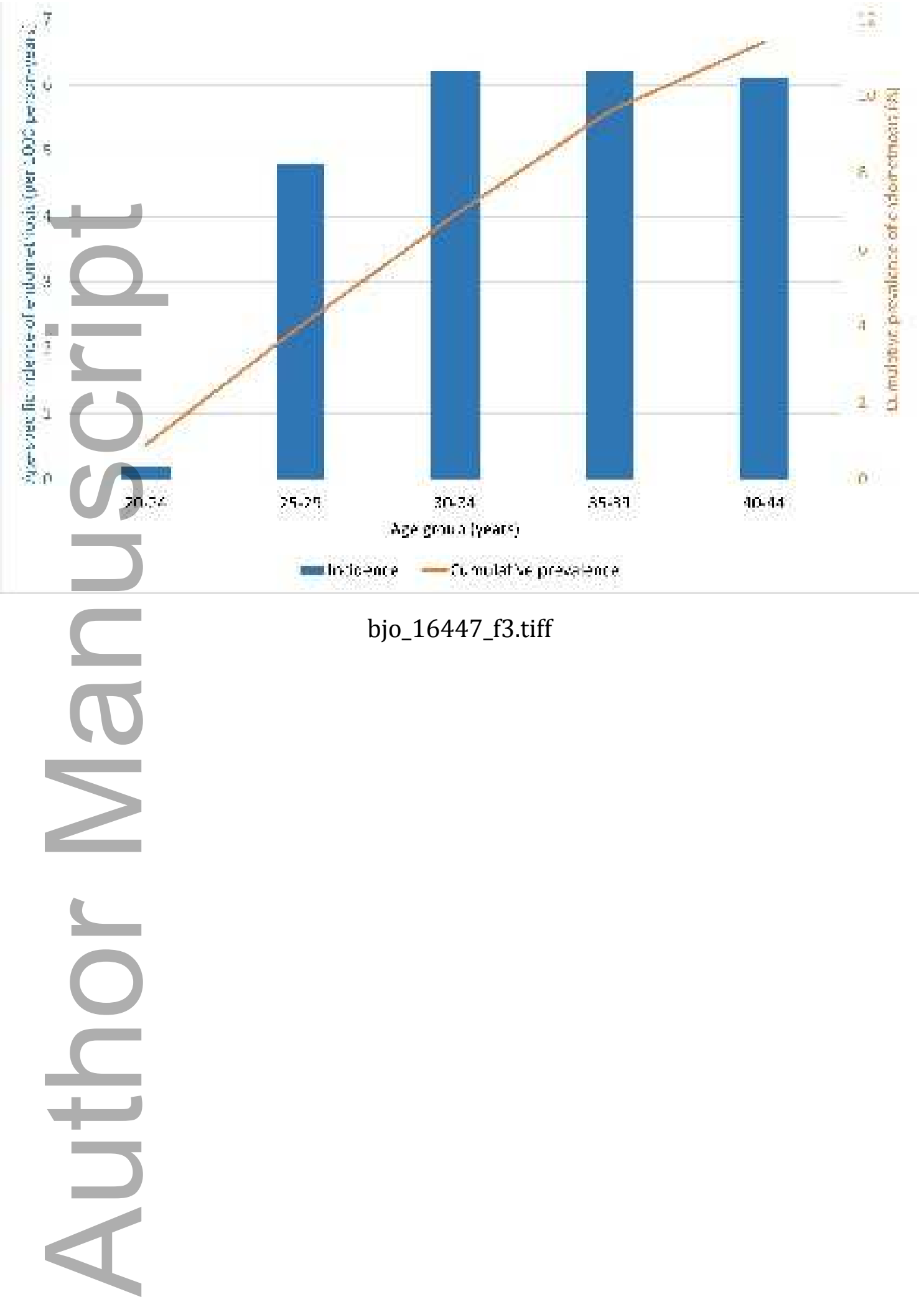




\section{University Library}

\section{- M M N E R VA A gateway to Melbourne's research publications}

Minerva Access is the Institutional Repository of The University of Melbourne

Author/s:

Rowlands, IJ;Abbott, JA;Montgomery, GW;Hockey, R;Rogers, P;Mishra, GD

Title:

Prevalence and incidence of endometriosis in Australian women: a data linkage cohort study

Date:

2020-09-01

\section{Citation:}

Rowlands, I. J., Abbott, J. A., Montgomery, G. W., Hockey, R., Rogers, P. \& Mishra, G. D. (2020). Prevalence and incidence of endometriosis in Australian women: a data linkage cohort study. BJOG-AN INTERNATIONAL JOURNAL OF OBSTETRICS AND GYNAECOLOGY, 128 (4), pp.657-665. https://doi.org/10.1111/1471-0528.16447.

Persistent Link:

http://hdl.handle.net/11343/276221 